\title{
The Effects of Protective Ventilation on the Production of Endogenous Melatonin and Prognosis in Patients Undergoing Esophageal Cancer Surgery: A Prospective Randomized Double- Blind Controlled Study
}

\section{Lixia Wang}

First Affiliated Hospital of Anhui Medical University

Jun Li

First Affiliated Hospital of Anhui Medical University

\section{Yuting Huang}

Anhui Medical University

\section{Yan Zhu}

First Affiliated Hospital of Anhui Medical University

\section{Qiying Shen}

First Affiliated Hospital of Anhui Medical University

\section{Hongyun Zou}

First Affiliated Hospital of Anhui Medical University

Xuesheng Liu ( $\sim$ liuxuesheng@ahmu.edu.cn )

First Affiliated Hospital of Anhui Medical University https://orcid.org/0000-0003-4324-282X

\section{Research article}

Keywords: ventilator-induced lung injury, one-lung ventilation, NLRP3 inflammasome, endogenous melatonin, inflammation.

Posted Date: August 13th, 2020

DOI: https://doi.org/10.21203/rs.3.rs-52115/v1

License: (c) (1) This work is licensed under a Creative Commons Attribution 4.0 International License. Read Full License 


\section{Abstract}

Background: Exogenous melatonin exerts a similar effect to protective ventilation on attenuating ventilator-induced lung injury (VILI) by inhibiting NLRP3 inflammasome activation in mouse model. However, the effect of protective ventilation on the production of endogenous melatonin and prognosis in patients undergoing esophageal cancer surgery remains unknown. In this study, we aimed to reveal the effects of protective ventilation on the production of endogenous melatonin, interleukin (IL)-1 $\beta$, IL-18 and major complications in patients undergoing esophageal cancer surgery.

Methods: Eight-eight patients were randomized to receive "conventional" ventilation ( $\mathrm{Vt}=10 \mathrm{~mL} / \mathrm{kg})$ or lung protective ventilation [ $\mathrm{Vt}=5 \mathrm{~mL} / \mathrm{kg}$ along with $5 \mathrm{~cm}$ of $\mathrm{H}_{2} \mathrm{O}$ positive end-expiratory pressure (PEEP)]. IL-1 $\beta$, IL-18 and melatonin levels in bronchoalveolar lavage fluid (BALF) and serum were measured. Respiratory variables and outcomes were evaluated.

Results: Lung protective ventilation decreased the peak airway pressure (Ppeak), plateau airway pressure (Pplat) and driving pressure $(\Delta \mathrm{P})$ compared with the "conventional" ventilation group. Lung protective ventilation inhibited polymorphonuclear $(P M N)$ cells invasion into the BALF $(P=0.000)$. Likewise, lung protective ventilation suppressed alveolar and serum IL-1 $\beta$ and IL-18 secretion after mechanical ventilation. Furthermore, lung protective ventilation resulted in a decrease in the inhibition of endogenous MT production compared to "conventional" ventilation ( $P=0.000)$. In addition, lung protective ventilation reduced the incidence of postoperative pulmonary complications $(P=0.04)$ and the rate of major postoperative complications $(P=0.023)$.

Conclusions: Taken together, lung protective ventilation for esophageal cancer surgery suppressed the secretion of IL-1 $\beta$, IL-18 and restored the endogenous melatonin level. Meanwhile, lung protective ventilation improved postoperative outcomes after esophageal cancer surgery.

Trial registration: The Chinese Clinical Trial Registry, ChiCTR1900026190. Registered 25 September 2019, http://www.chictr.org.cn/edit.aspx?pid=34677\&htm=4

\section{Background}

One-lung ventilation (OLV) is required for esophageal cancer and can contribute to the surgical field [1]. However, inappropriate ventilation modes may cause or augment acute lung injury, which is known as ventilator-induced lung injury (VILI) [2]. Lung protective ventilation [low tidal volume + positive endexpiratory pressure (PEEP)] was shown to achieve good clinical effects and protect against VILI [3, 4]. Furthermore, clinical studies have demonstrated that lung protective ventilation induced an immune response with lower concentrations of inflammatory mediators than that of "conventional" ventilation [5]. Therefore, further studies of the effect of lung protective ventilation on the pulmonary immune response are essential to prevent VILI. 
Increasing studies have shown that OLV may lead to proinflammatory cytokine release and inflammatory signaling pathway activation [5-8]. Overdistension in ventilated lungs followed by compression of alveolar vessels initiates a robust release of proinflammatory cytokines, such as interleukin (IL)-6, IL-8 and tumor necrosis factor (TNF)-a, in bronchoalveolar lavage fluid (BALF) $[5,9]$. These proinflammatory cytokines are important chemotactic factors for polymorphonuclear (PMN) cells [10]. Excessive PMN cell aggregation will amplify the inflammatory cascade. Furthermore, a recent study showed that in mouse alveolar macrophages, Nucleotide-binding domain and leucine-rich repeat protein 3 (NLRP3) inflammasome activation contributes to the development of VILI [11].

Melatonin (N-acetyl-5-methoxytryptamine, MT), which is mainly secreted in the pineal gland, has welldocumented anti-inflammatory and immunomodulatory functions $[12,13]$. Early preliminary studies have shown that exogenous MT ameliorates VILI by increasing the anti-inflammatory response [14]. Recently, Zhang et al. demonstrated that exogenous MT inhibited NLRP3 inflammasome activation in mice with acute lung injury [15]. However, researchers have not determined whether lung protective ventilation affects NLRP3 inflammasome-related inflammatory cytokine and endogenous melatonin production in patients.

Our study aimed to investigate the effects of lung protective ventilation on NLRP3 inflammasome-related inflammatory cytokine and endogenous MT secretion in patients undergoing video-assisted thoracoscopic esophagectomy (VATS). In addition, the effect of lung protective ventilation on postoperative complications was also investigated.

\section{Materials And Methods}

\section{Study Design}

Patients scheduled for elective VATS at the First Affiliated Hospital of Anhui Medical University (Anhui, China) were included in the study. The study protocol had received prior approval from the Ethics Committee of the First Affiliated Hospital of Anhui Medical University (No. 20190385), and this trial was registered in the Chinese Clinical Trial Registry (No. ChiCTR1900026190). Before participation in the study, all patients provided informed consent.

\section{Study Population}

Patients with esophageal cancer who were treated at our hospital were considered for enrollment. The

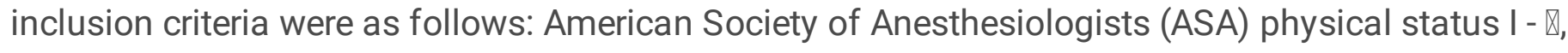
requirement for OLV during operation, and aged 45-77 years. Exclusion criteria were preexisting hypoxemia, diagnosed major obstructive or restrictive pulmonary disease [preoperative forced expiratory volume in 1 second (FEV1) and forced vital capacity (FVC) $<70 \%$ of the predicted value], pulmonary infection before surgery, body mass index (BMI) of less than 20 or more than 35 , and use of immune modulators. 


\section{Randomization and Blinding}

The randomized numbers were generated by a research coordinator using block sizes on a 1:1 ratio. This ensured that each group had an equal number of subjects. Then, the research coordinator sealed the numbers in opaque envelopes. Before mechanical ventilation, the anesthesia assistant opened the envelopes, set the breathing parameters and covered the breathing parameters using opaque paper. The anesthesia assistant did not participate in the next study. One anesthesiologist collected the specimens, and another anesthesiologist recorded the breathing parameters. Both physicians were blinded to the allocation.

\section{Study Protocol}

Standard monitoring devices were applied after admission to the operating room. Before induction of anesthesia, an artery catheter was inserted into the left radial artery. Anesthesia induction was performed with $2.0-2.5 \mathrm{mg} / \mathrm{kg}$ propofol, $0.02-0.06 \mathrm{mg} / \mathrm{kg}$ midazolam, $0.4-0.6 \mu \mathrm{g} / \mathrm{kg}$ sufentanil and $0.6-0.9 \mathrm{mg} / \mathrm{kg}$ rocuronium. 3 min after assisted breathing, a double-lumen endotracheal tube (Broncho-Cath ${ }^{\circledR} 35 \mathrm{~F}$ or 37 F; Covidien, Ireland) was inserted into the left main bronchus. Anesthesia was maintained with $50-100$ $\mu \mathrm{g} / \mathrm{kg} / \mathrm{min}$ of propofol, $0.1-1 \mu \mathrm{g} / \mathrm{kg} / \mathrm{min}$ of remifentanil and $5.0-10.0 \mu \mathrm{g} / \mathrm{kg} / \mathrm{min}$ of rocuronium to maintain the proper depth of anesthesia (BIS 40-60). A forced-air warming system (3M Company, Shanghai, China) was used to keep the patients warm.

After intubation, the patients were randomly divided into 2 groups. In the control group (group A), patients received volume controlled mechanical ventilation with a tidal volume of $10 \mathrm{~mL} / \mathrm{kg}$ of ideal body weight (IBW). In the lung protective ventilation group (group B), lung protective ventilation with a low tidal volume $(\mathrm{Vt}=5 \mathrm{~mL} / \mathrm{kg} \mathrm{IBW})$ and $5 \mathrm{~cm} \mathrm{H_{2 }} \mathrm{O}$ PEEP was chosen. After 15 minutes, all patients were turned to the left lateral position and OLV was initiated. During OLV, the ventilation mode was not changed except the plateau airway pressure (Pplat) exceeded $30 \mathrm{cmH}_{2} \mathrm{O}$. If the Pplat exceeded $30 \mathrm{cmH}_{2} \mathrm{O}$, the tidal volume was decreased and this patient discontinued the experiment. With both two-lung ventilation (TLV) and OLV, mechanical ventilation was performed with an inspiratory to expiratory ratio of 1:2, and an appropriate respiratory rate to maintain an end-tidal $\mathrm{CO}_{2}\left(\mathrm{ETCO}_{2}\right)$ below $45 \mathrm{mmHg}$. All surgeries were always performed at 8:30 in the morning.

\section{Observational Indexes}

Peak airway pressure (Ppeak), Pplat, respiratory rate and blood gas analyses were evaluated at two stages: during TLV before surgery and 30 minutes after OLV. Furthermore, the driving pressure $(\triangle P)$ was recorded. $\triangle P$ was defined and calculated as follows: $\triangle P=P$ plat-PEEP [16].

The major postoperative complications were pulmonary complications and nonpulmonary complications. The pulmonary complications included pulmonary infection, acute lung injury or acute 
respiratory distress syndrome and reintubation or invasive mechanical ventilation. Nonpulmonary complications included anastomotic fistula, incision infection, ICU stay and death before hospital discharge.

Bronchoalveolar lavage was performed after induction of general anesthesia (baseline) and at the end of the surgical procedures. BALF was aspirated from the lung after instillation of $20 \mathrm{~mL}$ of sterile isotonic saline. Then, the recovered BALF was centrifuged at $700 \mathrm{~g}$ for 10 minutes at $4^{\circ} \mathrm{C}$, and the supernatant was stored at $-80^{\circ} \mathrm{C}$. The cell pellets were resuspended in ice-cold sterile isotonic saline for staining and counting.

Blood samples were obtained during TLV after induction of general anesthesia (baseline) and at the end of the surgical procedures. Five milliliters of arterial blood samples was centrifuged at $800 \mathrm{~g}$ for 5 minutes. The upper serum phase was separated and stored at $-80^{\circ} \mathrm{C}$.

MT, IL-18 and IL-1 $\beta$ concentrations in the serum and BALF were determined using commercial ELISA kits (Cusabio, Wuhan, China). We performed the assays according to the manufacturer's instructions. The limitations for MT, IL-18 and IL-1 $\beta$ were $0.1 \mathrm{pg} / \mathrm{mL}, 7.8 \mathrm{pg} / \mathrm{mL}$ and $2.2 \mathrm{pg} / \mathrm{mL}$, respectively.

\section{Statistical Analysis}

According to previous studies, the cell numbers in the BALF increased by more than $30 \%$ after OLV [5], which required 12 patients per group with $\alpha=0.05$ and $\beta=0.02$; thus, we aimed to enroll 88 patients to allow for dropouts. The sample size was calculated using PASS 11.0 software.

Data are presented as the mean \pm SD or number of patients (proportion, \%). The independent-samples ttest or paired-samples t-test were used to analyze normally distributed data. Non-normally distributed data were analyzed by chi-square tests or Fisher's exact test. All statistical analyses were performed with SPSS 19, and a P value of $<0.05$ was considered significant.

\section{Results}

\section{Baseline Parameters of Patients}

88 patients were included and assessed. Four patients did not meet the criteria, and 84 were included in this study. However, two patients withdrew for technical reasons, and the other patient were excluded for higher Pplat. Finally, 81 patients completed the study (Fig. 1). The patient characteristics and preoperative details showed no significant differences between the two groups (Table 1). 
Table 1

Baseline parameters of patients

\begin{tabular}{|c|c|c|c|}
\hline & Group $A(n=40)$ & Group B $(n=41)$ & $\mathbf{P}$ \\
\hline Male/Female (n) & $36 / 4$ & $35 / 6$ & 0.529 \\
\hline Age (y) & $63.25 \pm 6.91$ & $64.46 \pm 6.95$ & 0.433 \\
\hline $\mathrm{BMI}\left(\mathrm{kg} / \mathrm{m}^{2}\right)$ & $23.93 \pm 2.20$ & $24.16 \pm 1.89$ & 0.614 \\
\hline Oxygenation index (mm Hg) & $409.78 \pm 21.91$ & $406.11 \pm 19.65$ & 0.431 \\
\hline $\mathrm{PaCO} 2(\mathrm{~mm} \mathrm{Hg})$ & $40.05 \pm 3.26$ & $40.29 \pm 2.99$ & 0.728 \\
\hline SpO2 (\%) & $98.63 \pm 1.08$ & $98.73 \pm 1.12$ & 0.663 \\
\hline FEV1(\%) & $86.58 \pm 6.12$ & $85.64 \pm 6.31$ & 0.500 \\
\hline $\mathrm{FVC}(\%)$ & $91.40 \pm 9.31$ & $88.65 \pm 6.39$ & 0.127 \\
\hline Operative time (min) & $291.60 \pm 35.41$ & $293.46 \pm 40.97$ & 0.827 \\
\hline OLV time (min) & $110.25 \pm 24.17$ & $118.15 \pm 25.06$ & 0.153 \\
\hline \multicolumn{4}{|c|}{$\begin{array}{l}\text { Data were presented as numbers or the mean } \pm \mathrm{SD} \text {. Group } \mathrm{A} \text { : the patients chose volume controlled } \\
\text { mechanical ventilation with a routine tidal volume }(\mathrm{Vt}=10 \mathrm{~mL} / \mathrm{kg}) \text { as control; Group } \mathrm{B} \text { : the patients } \\
\text { chose lung protective ventilation with a low tidal volume }(\mathrm{Vt}=5 \mathrm{~mL} / \mathrm{kg}) \text { and } 5 \mathrm{~cm} \mathrm{H}_{2} \mathrm{O} \mathrm{PEEP} \text {. } \mathrm{BMI} \text { : } \\
\text { body mass index; } \mathrm{PaO}_{2} \text { : arterial oxygen tension; } \mathrm{FiO}_{2} \text { : fraction of inspired oxygen; } \mathrm{PaCO}_{2} \text { : arterial } \\
\text { carbon dioxide tension; FEV1: forced expiratory volume; FVC: forced vital capacity; OLV: one-lung } \\
\text { ventilation; } \mathrm{SpO}_{2} \text {, oxygen saturation. }\end{array}$} \\
\hline
\end{tabular}

\section{Changes In Respiratory Parameters}

The respiratory and gas exchange variables are presented in Table 2. The Ppeak, Pplat and $\Delta \mathrm{P}$ were significantly decreased in the protective ventilation group. While the respiratory rate increased substantially compared with that in the control group. Additionally, the oxygenation index in the protective ventilation group was higher than that in the control group at 30 minutes after OLV $(P=0.006)$. 
Table 2

Respiratory variables and Oxygenation Index During TLV Before Surgery (At baseline) and During OLV (After $30 \mathrm{~min}$ )
Group A $(n=40)$
Group B $(n=41)$
$\mathbf{P}$

Peak pressure $\left(\mathrm{cm} \mathrm{H}_{2} \mathrm{O}\right)$

$\begin{array}{lccc}\text { At baseline } & 14.85 \pm 2.38 & 13.41 \pm 1.53 & 0.002^{\mathrm{a}} \\ 30 \text { min after OLV } & 26.63 \pm 1.93 & 22.22 \pm 2.12 & <10^{- \text {3a }}\end{array}$

Plateau pressure $\left(\mathrm{cm} \mathrm{H}_{2} \mathrm{O}\right)$

$\begin{array}{lccc}\text { At baseline } & 11.78 \pm 2.19 & 10.49 \pm 1.52 & 0.003^{\mathrm{a}} \\ 30 \mathrm{~min} \text { after OLV } & 22.90 \pm 2.13 & 19.00 \pm 1.99 & <10^{-3 a}\end{array}$

Driving pressure $\left(\mathrm{cm} \mathrm{H}_{2} \mathrm{O}\right)$

$\begin{array}{llll}\text { At baseline } & 11.78 \pm 2.19 & 5.49 \pm 1.52 & <10^{- \text {3а }} \\ 30 \text { min after OLV } & 22.90 \pm 2.13 & 14.00 \pm 1.99 & <10^{- \text {3a }}\end{array}$

\section{Oxygenation index $(\mathrm{mmHg})$}

\begin{tabular}{llll}
\hline At baseline & $406.42 \pm 30.38$ & $407.57 \pm 26.72$ & 0.857 \\
\hline 30 min after OLV & $314.70 \pm 26.02$ & $332.57 \pm 30.52$ & $0.006^{\text {a }}$
\end{tabular}

\section{Respiratory rate (bpm)}

\begin{tabular}{lccc} 
At baseline & $10.408 \pm 1.61$ & $14.39 \pm 1.24$ & $<10^{-3 а}$ \\
\hline 30 min after OLV & $13.35 \pm 1.08$ & $17.54 \pm 1.03$ & $<10^{-3 a}$
\end{tabular}

Data were presented as the mean and SD. Group A: the patients chose volume controlled mechanical ventilation with a routine tidal volume $(\mathrm{Vt}=10 \mathrm{~mL} / \mathrm{kg})$ as control; Group B: the patients chose lung protective ventilation with a low tidal volume $(\mathrm{Vt}=5 \mathrm{~mL} / \mathrm{kg})$ and $5 \mathrm{~cm} \mathrm{H} \mathrm{H}_{2} \mathrm{O} P E E P$. OLV: one-lung ventilation; TLV: two-lung ventilation. a Compared Group A with Group B, P $<0.05$

\section{Changes In The Number Of Cells In The Balf}

The cells in the BALF were counted after Wright-Giemsa staining. The number of total cells (in groups A and $B, P=0.000$ ) and $P M N$ cells (in groups $A$ and $B, P=0.000$ ) in the BALF were substantially increased after mechanical ventilation (Fig. 2). However, in the group treated with the lung-protective strategy, the total cells $(P=0.000)$ and $P M N$ cells $(P=0.000)$ in the BALF were significantly reduced compared to the control group (Fig. 2). 
Commercial ELISA kits were used to detect the levels of both IL-1 $\beta$ and IL-18 in the BALF and serum. The IL-1 $\beta$ and IL-18 levels in the BALF and serum showed an increasing trend after mechanical ventilation (Fig. 3A, B, D and E). However, lung protective ventilation resulted in a significant decrease in the BALF and serum IL-1 $\beta$ and IL-18 concentrations compared to the control group (Fig. 3A, B, D and E).

\section{Changes In Mt Levels In The Balf And Serum}

Endogenous MT levels in both the BALF and serum were also detected. In contrast to the IL-18 and IL-1 $\beta$ levels, the BALF and serum MT levels were significantly decreased in both groups after mechanical ventilation (Fig. 3C, F). Additionally, lower BALF and serum MT concentrations were observed in the control group than in the lung protective ventilation group (Fig. $3 \mathrm{C}$ and $\mathrm{F}$ ).

\section{The Incidence Of Complications}

Pulmonary complications occurred in $2 / 41(4.88 \%)$ patients in the protective ventilation group and 8/40 $(20 \%)$ patients in the control group $(P=0.04) .2(4.88 \%)$ patient in the protective ventilation group developed a nonpulmonary complication compared with $4(10 \%)$ patients in the control group $(P=0.382)$. The rate of major postoperative complications was $9.76 \%$ and $30 \%$ in the protective ventilation group and control group, respectively $(P=0.023)$. The incidence of major postoperative complications was lower in the lung protection group than in the control group (Table 3 ). 
Table 3

Outcomes analysis

\begin{tabular}{|c|c|c|c|}
\hline & Group A $(n=40)$ & Group B $(n=41)$ & $\mathbf{P}$ \\
\hline Incidence of Complications (\%) & $12(30 \%)$ & $4(9.76 \%)$ & $0.023^{\mathrm{a}}$ \\
\hline Pulmonary complications & $8(20 \%)$ & $2(4.88 \%)$ & $0.040^{\mathrm{a}}$ \\
\hline Pulmonary infection & 4 & 1 & 0.160 \\
\hline ALI/ARDS & 2 & 1 & 0.544 \\
\hline Reintubation & 2 & 0 & 0.150 \\
\hline Nonpulmonary complications & $4(10 \%)$ & $2(4.88 \%)$ & 0.382 \\
\hline Anastomotic fistula & 1 & 1 & 0.986 \\
\hline Incision infection & 1 & 1 & 0.986 \\
\hline ICU stay & 2 & 0 & 0.150 \\
\hline Hospital death & 0 & 0 & 1.0 \\
\hline \multicolumn{4}{|c|}{$\begin{array}{l}\text { Date were presented as numbers and percentage. ALI: acute lung injury; ARDS: acute respiratory } \\
\text { distress syndrome. Group A: the patients chose volume controlled mechanical ventilation with a } \\
\text { routine tidal volume }(\mathrm{Vt}=10 \mathrm{~mL} / \mathrm{kg}) \text { as control; Group B: the patients chose lung protective ventilation } \\
\text { with a low tidal volume }(\mathrm{Vt}=5 \mathrm{~mL} / \mathrm{kg}) \text { and } 5 \mathrm{~cm} \mathrm{H} \mathrm{H}_{2} \mathrm{O} \text { PEEP. a Compared Group A with Group B, } \mathrm{P}< \\
0.05\end{array}$} \\
\hline
\end{tabular}

\section{Discussion}

As shown in the present study, lung protective ventilation improved respiratory variables, including Ppeak, Pplat and $\triangle \mathrm{P}$. Lung protective ventilation not only inhibited PMN cell invasion but also suppressed IL-1 $\beta$ and IL-18 secretion. Lung protective ventilation resulted in a decrease in the inhibition of endogenous MT production compared to "conventional" ventilation. In addition, lung protective ventilation decreased the incidence of pulmonary complications and major postoperative complications.

OLV is an established procedure performed during VATS. However, clinical studies have shown that the extended use of OLV is an independent risk factor for postoperative pulmonary dysfunction [17]. Excessive stretching or repeated opening of lung tissues is an important cause of VILI during OLV [18]. A lung-protective strategy using low Vt along with PEEP during OLV was confirmed to improve postoperative pulmonary dysfunction [6]. In our study, the lung-protective strategy notably decreased Ppeak and Pplat, indicating that the shear force was reduced by the lung-protective strategy. Meanwhile, we also observed a substantial decrease in $\Delta \mathrm{P}$ with the lung-protective strategy, which suggested that the lung-protective strategy was associated with a reduced incidence of postoperative pulmonary complications [16]. Indeed, postoperative pulmonary complications occurred less frequently in the lung protective ventilation group in our study. 
Increased mechanical strain further activating the inflammatory response is a key event during the development of VILI [5]. The results from previous and recent studies have shown that IL-1 $\beta$ is a special proinflammatory cytokine that promotes VILI in animal models and patients [19-22]. Regulation and inhibition of IL-1 $\beta$ can finally achieve organ protection because blockade of the IL-1 receptor has been demonstrated to inhibit neutrophil sequestration and edema formation in VILI [23]. In our study, mechanical ventilation clearly increased the alveolar and serum concentration of IL-1 $\beta$ and the alveolar PMN cell counts in the BALF. However, lung protective ventilation blocked the elevated IL-1 $\beta$ level and PMN cell infiltration. Most interestingly, we observed a dramatic increase in both the alveolar and serum concentrations of IL-18 after OLV, while lung protective ventilation resulted in a profound reduction in IL18 levels. IL-1 $\beta$ and IL-18 were confirmed to be products of NLRP3 inflammasome activation [24]. Furthermore, current studies have demonstrated that NLRP3 inflammasome activation plays a key role in the pathogenesis of VILI in a mouse model $[25,26]$. Therefore, lung protective ventilation may inhibit inflammatory responses by inhibiting the activation of the NLRP3 inflammasome. For the first time, we showed that mechanical ventilation may activate the NLRP3 inflammasome, and lung protective ventilation seems to inhibit the NLRP3 inflammasome activation in patients.

In recent years, the anti-inflammatory effects of both exogenous and endogenous MT have been observed in many conditions [27, 28]. Paula et al. demonstrated that the exogenous addition of MT protected against VILI through decreasing the levels of inflammatory cytokines in a mouse model [14]. Further research confirmed that exogenous replenishment of MT alleviated lipopolysaccharide-induced acute lung injury by inhibiting NLRP3 inflammasome activation [15]. However, researchers have not determined whether VILI affects the production of endogenous MT. Therefore, we hypothesized that endogenous MT may play a pivotal role in the pathogenesis of VILI. As expected, mechanical ventilation substantially reduced the levels of endogenous MT in patient serum and BALF. Surprisingly, pulmonary protective ventilation significantly inhibited the reduction of endogenous MT. Accordingly, our results suggested that endogenous MT may be involved in the pathogenesis of VILI, and pulmonary protective ventilation may attenuate VILI by restoring the level of endogenous MT in patients.

As described above, lung protective ventilation not only improved respiratory parameters but also suppressed NLRP3 inflammasome-related inflammatory cytokine secretion and restored the level of endogenous MT: which are likely to be required to improve outcomes during esophageal surgery. Indeed, lung protective ventilation not only reduced the incidence of pulmonary complications but also decreased the rate of major postoperative complications in our study, consistent with the results reported by Marret [29].

This study has some limitations. First, the sizes of the samples were small, which may lead to bias. Second, based on our data, we were unable to conclusively determine the relationship between inflammasome-related inflammatory cytokines and endogenous MT. Therefore, the crosstalk between endogenous MT and the NLRP3 inflammasome in VILI requires further animal experiments.

\section{Conclusions}


In conclusion, pulmonary protective ventilation improved outcomes by decreasing the rate of pulmonary complications and major postoperative complications. These effects may be attributed to the ability of pulmonary protective ventilation to suppress NLRP3 inflammasome-related inflammatory cytokine secretion and restore the level of endogenous MT in patients undergoing VATS.

\section{Abbreviations}

OLV

one-lung ventilation

VILI

ventilator-induced lung injury

PEEP

positive end-expiratory pressure

IL

interleukin

TNF

tumor necrosis factor

BALF

bronchoalveolar lavage fluid

PMN

polymorphonuclear

NLRP3

Nucleotide-binding domain and leucine-rich repeat protein 3

MT

melatonin

FEV

forced expiratory volume

FVC

forced vital capacity

$\mathrm{BMI}$

body mass index

TLV

two-lung ventilation

IBW

ideal body weight

ETCO2

end-tidal pressure of carbon dioxide

Ppeak

peak airway pressure

Pplat 
plateau airway pressure

$\Delta \mathrm{P}$

driving pressure

\section{Declarations}

\section{Ethics approval and consent to participate}

The study protocol had received prior approval by the Ethics Committee of the First Affiliated Hospital of Anhui Medical University (No. 20190385). In the study, all patients signed written informed consent.

\section{Consent for publication}

All authors have consented to publication of the manuscript.

\section{Availability of data and materials}

The datasets generated and/or analyzed during the current study are available from the corresponding author on reasonable request.

\section{Competing interests}

The authors declare no conflicts of interests.

\section{Funding}

This work was supported by grants from the National Nature Science Foundation of China (No. 81902003), Youth Research Foundation of the Anhui Medical University First Affiliated Hospital (Nos. 2018kj28 and 2019kj11), Doctoral Research Foundation of the First Affiliated Hospital of Anhui Medical University (No. 1326).

\section{Authors' Contributions}

LXW, JL and YTH collected the data, and drafted the manuscript, they contributed equally as co-first authors; YZ performed the statistical analysis; QYS and HYZ revised the manuscript critically for important intellectual content. All authors were responsible for the conception and design of the trial, and approved the final manuscript. 


\section{Acknowledgments}

We acknowledge the support by Dr. Zhilai Yang. We are also thankful to the patients and their families who consented to participate in our trial.

\section{References}

1. Blank RS, Colquhoun DA, Durieux ME, et al. Management of One-lung Ventilation: Impact of Tidal Volume on Complications after Thoracic Surgery. Anesthesiology. 2016;124(6):1286-95.

2. Choi YS, Shim JK, Na S, et al. Pressure-controlled versus volume-controlled ventilation during onelung ventilation in the prone position for robot-assisted esophagectomy. Surgical endoscopy. 2009;23(10):2286-91.

3. Hemmes SN, Serpa Neto A, Schultz MJ. Intraoperative ventilatory strategies to prevent postoperative pulmonary complications: a meta-analysis. Curr Opin Anaesthesiol. 2013;26(2):126-33.

4. Fernandez-Perez ER, Keegan MT, Brown DR, et al. Intraoperative tidal volume as a risk factor for respiratory failure after pneumonectomy. Anesthesiology. 2006;105(1):14-8.

5. Schilling T, Kozian A, Huth $\mathrm{C}$, et al. The pulmonary immune effects of mechanical ventilation in patients undergoing thoracic surgery. Anesthesia analgesia. 2005;101(4):957-65. table of contents.

6. Senturk M, Slinger P, Cohen E. Intraoperative mechanical ventilation strategies for one-lung ventilation. Best practice research Clinical anaesthesiology. 2015;29(3):357-69.

7. Kotani N, Lin CY, Wang JS, et al. Loss of alveolar macrophages during anesthesia and operation in humans. Anesthesia analgesia. 1995;81(6):1255-62.

8. Kotani N, Hashimoto H, Sessler DI, et al. Intraoperative modulation of alveolar macrophage function during isoflurane and propofol anesthesia. Anesthesiology. 1998;89(5):1125-32.

9. Lohser J, Slinger P, Lung Injury After One-Lung Ventilation. A Review of the Pathophysiologic Mechanisms Affecting the Ventilated and the Collapsed Lung. Anesthesia analgesia. 2015;121(2):302-18.

10. Dreyfuss D, Ricard JD, Saumon G. On the physiologic and clinical relevance of lung-borne cytokines during ventilator-induced lung injury. Am J Respir Crit Care Med. 2003;167(11):1467-71.

11. Wu J, Yan Z, Schwartz DE, et al. Activation of NLRP3 inflammasome in alveolar macrophages contributes to mechanical stretch-induced lung inflammation and injury. Journal of immunology (Baltimore, Md: 1950). 2013;190(7):3590-3599.

12. Liu YJ, Meng FT, Wang LL, et al. Apolipoprotein E influences melatonin biosynthesis by regulating NAT and MAOA expression in C6 cells. Journal of pineal research. 2012;52(4):397-402.

13. Calvo JR, Gonzalez-Yanes C, Maldonado MD. The role of melatonin in the cells of the innate immunity: a review. Journal of pineal research. 2013;55(2):103-20.

14. Pedreira PR, Garcia-Prieto E, Parra D, et al. Effects of melatonin in an experimental model of ventilator-induced lung injury. American journal of physiology Lung cellular molecular physiology. 
2008;295(5):L820-7.

15. Zhang Y, Li X, Grailer JJ, et al. Melatonin alleviates acute lung injury through inhibiting the NLRP3 inflammasome. Journal of pineal research. 2016;60(4):405-14.

16. Neto AS, Hemmes SN, Barbas CS, et al. Association between driving pressure and development of postoperative pulmonary complications in patients undergoing mechanical ventilation for general anaesthesia: a meta-analysis of individual patient data. The Lancet Respiratory medicine. 2016;4(4):272-80.

17. Della Rocca G, Coccia C. Acute lung injury in thoracic surgery. Curr Opin Anaesthesiol. 2013;26(1):40-6.

18. Kim KN, Kim DW, Jeong MA, et al. Comparison of pressure-controlled ventilation with volumecontrolled ventilation during one-lung ventilation: a systematic review and meta-analysis. BMC anesthesiology. 2016;16(1):72.

19. Belperio JA, Keane MP, Lynch JP 3. The role of cytokines during the pathogenesis of ventilatorassociated and ventilator-induced lung injury. Semin Respir Crit Care Med. 2006;27(4):350-64. rd, et al.

20. Lionetti V, Recchia FA, Ranieri VM. Overview of ventilator-induced lung injury mechanisms. Curr Opin Crit Care. 2005;11(1):82-6.

21. Wagner J, Strosing KM, Spassov SG, et al. Sevoflurane posttreatment prevents oxidative and inflammatory injury in ventilator-induced lung injury. PloS one. 2018;13(2):e0192896.

22. Conway Morris A, Kefala K, Wilkinson TS, et al. Diagnostic importance of pulmonary interleukin1 beta and interleukin-8 in ventilator-associated pneumonia. Thorax. 2010;65(3):201-7.

23. Frank JA, Pittet JF, Wray C, et al. Protection from experimental ventilator-induced acute lung injury by IL-1 receptor blockade. Thorax. 2008;63(2):147-53.

24. Bryant C, Fitzgerald KA. Molecular mechanisms involved in inflammasome activation. Trends in cell biology. 2009;19(9):455-64.

25. Liu H, Gu C, Liu M, et al. Ventilator-induced lung injury is alleviated by inhibiting NLRP3 inflammasome activation. Molecular immunology. 2019;111:1-10.

26. An $X$, Sun $X$, Yang $X$, et al Oxidative stress promotes ventilator-induced lung injury through activating NLRP3 inflammasome and TRPM2 channel. Artificial cells, nanomedicine, and biotechnology. 2019;47(1):3448-3455.

27. Mauriz JL, Collado PS, Veneroso C, et al. A review of the molecular aspects of melatonin's antiinflammatory actions: recent insights and new perspectives. Journal of pineal research. 2013;54(1):1-14.

28. Wu HM, Shen QY, Fang L, et al. JNK-TLR9 signal pathway mediates allergic airway inflammation through suppressing melatonin biosynthesis. Journal of pineal research. 2016;60(4):415-23.

29. Marret $E$, Cinotti R, Berard $L$, et al. Protective ventilation during anaesthesia reduces major postoperative complications after lung cancer surgery: A double-blind randomised controlled trial. 
Eur J Anaesthesiol. 2018;35(10):727-35.

\section{Figures}

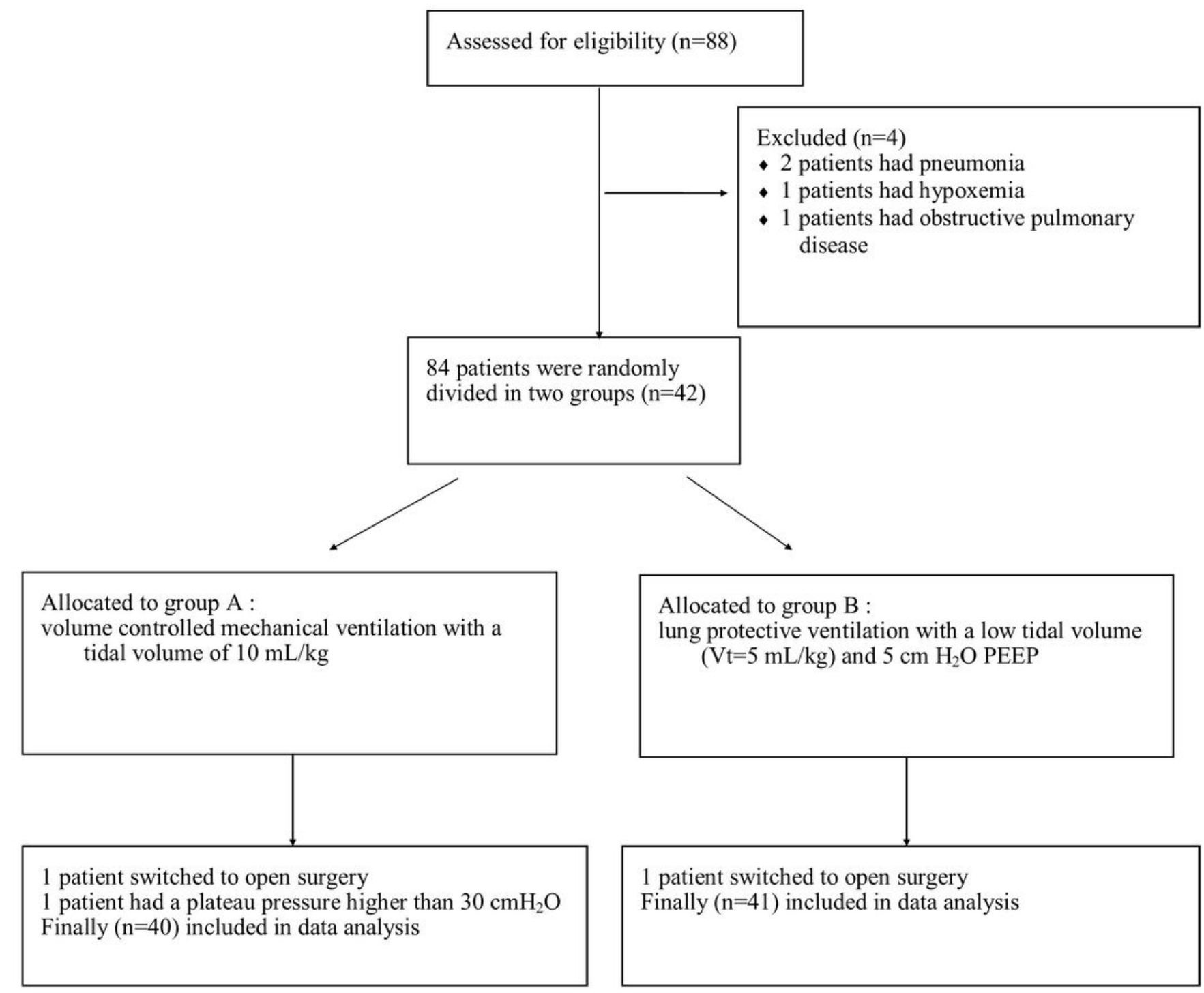

\section{Figure 1}

Consort flow chart that outline patients assignment and treatment protocols. Group A: Volume controlled mechanical ventilation with a tidal volume of $10 \mathrm{~mL} / \mathrm{kg}$ was used; Group B: lung protective ventilation with a low tidal volume $(\mathrm{Vt}=5 \mathrm{~mL} / \mathrm{kg} \mathrm{IBW})$ and $5 \mathrm{~cm} \mathrm{H} 2 \mathrm{O}$ PEEP was chosen. 


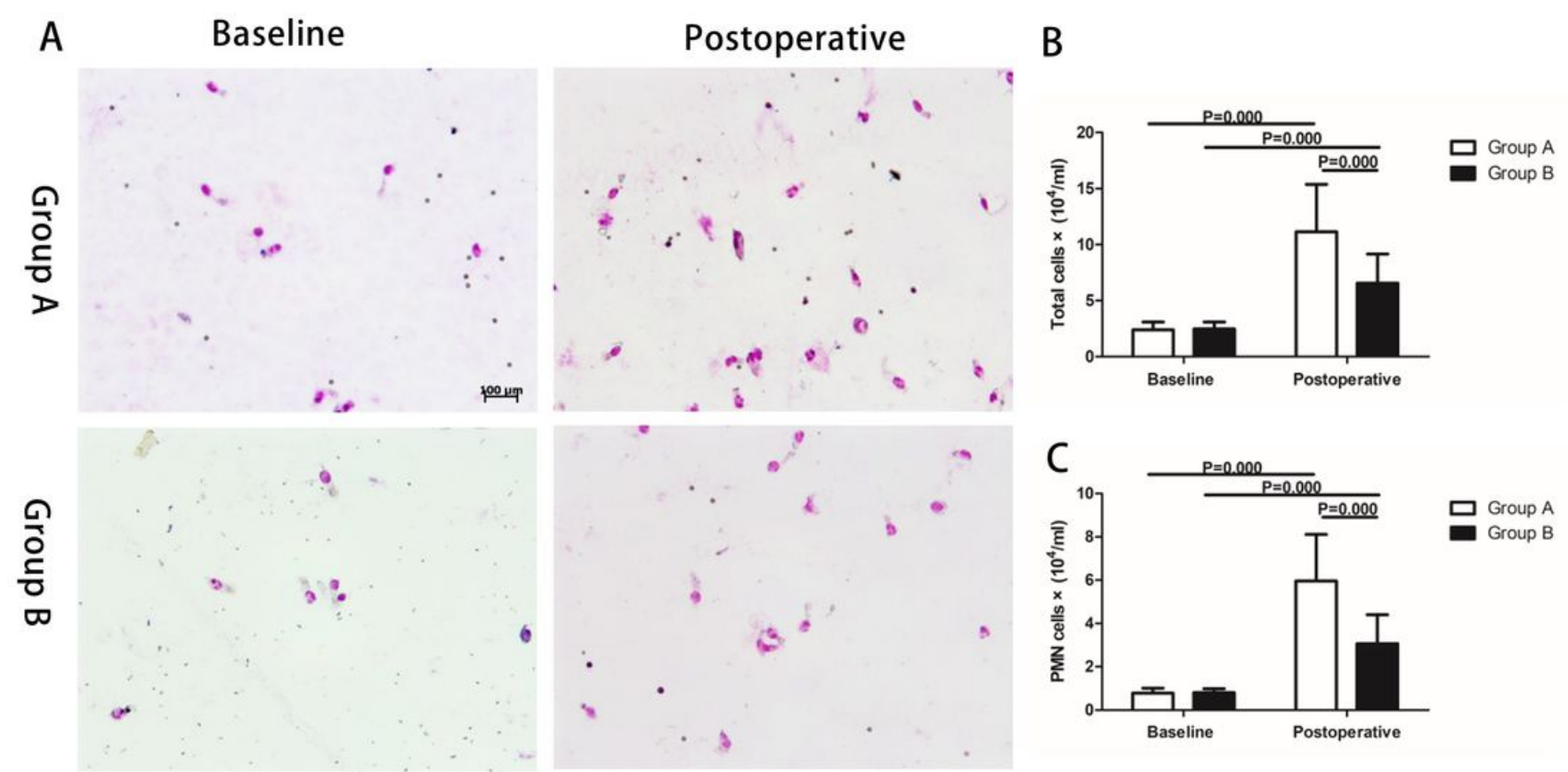

Figure 2

Effect of lung protective ventilation on polymorphonuclear (PMN) cells in BALF. (A) Representative Wright-Giemsa stained smear of BALF from different groups (magnification $\times 20$ ). Data shown represent changes in the total number of cells (B), PMN cells (C) in the BALF. Data are expressed as the mean \pm SD of 30 patients per group. 

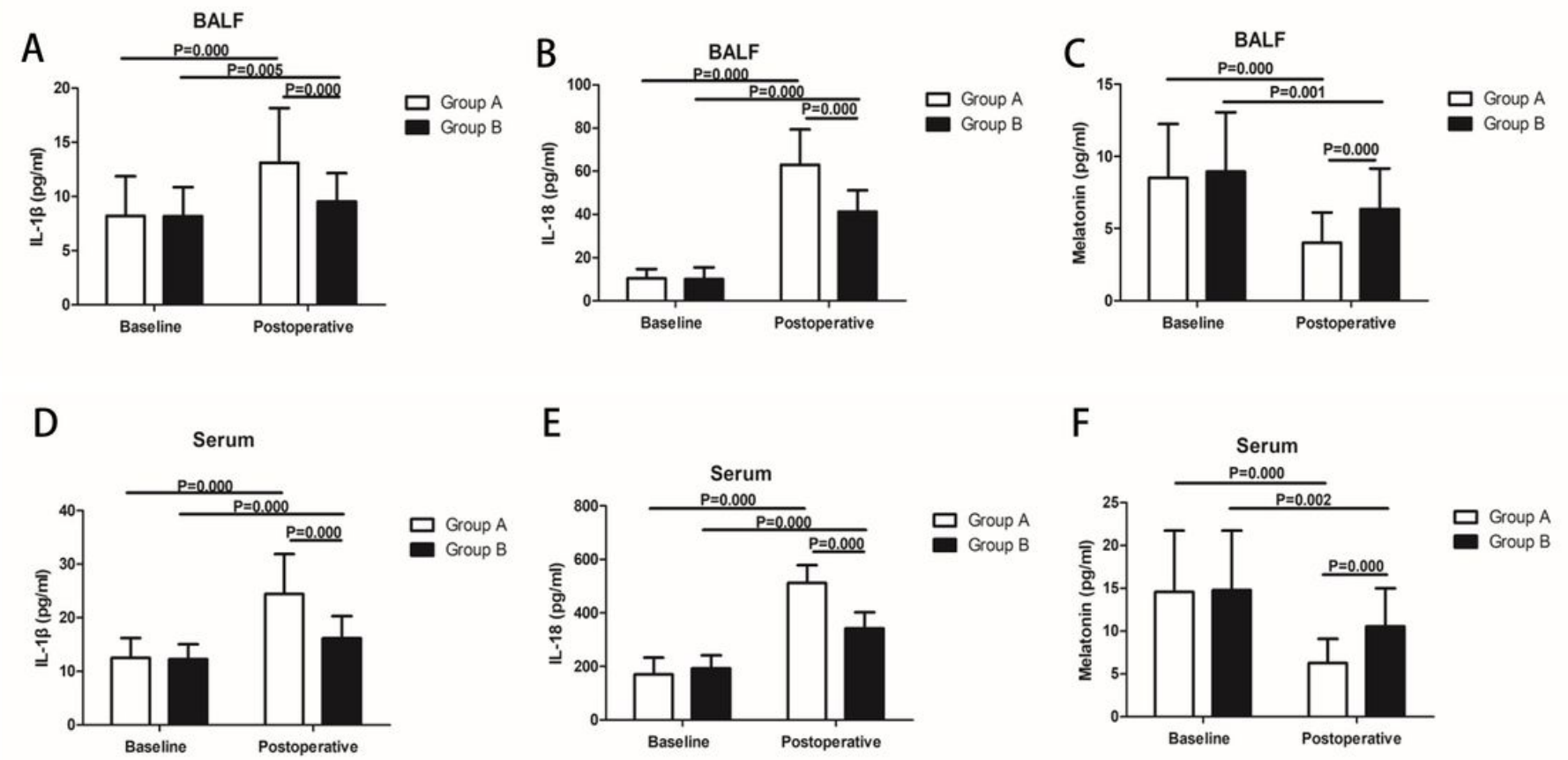

Figure 3

Effect of lung protective ventilation on IL-1 $\beta$, IL-18 and endogenous melatonin production in BALF and serum. (A-C) Productions of IL-1 $\beta$, IL-18 and endogenous melatonin in the BALF. (D-F) Productions of IL$1 \beta, \mathrm{IL}-18$ and endogenous melatonin in the serum. Data are expressed as the mean \pm SD of 30 patients per group.

\section{Supplementary Files}

This is a list of supplementary files associated with this preprint. Click to download.

- CONSORT2010ChecklistMSWord.doc 